\title{
Asesores de tesis y publicación de artículos científicos en el pregrado
}

\author{
Thesis advisors and publication of scientific articles in undergraduate
}

\section{Sr. Editor:}

Leímos con mucho interés el artículo publicado por Alarcon-Ruiz \& Quezada (1), sobre la publicación de artículos científicos por asesores de tesis de una Facultad de Medicina. El tema tratado es importante pues en el ámbito universitario existe una deficiencia en lograr que las investigaciones terminen siendo publicadas y por el contrario se estimula una cultura de investigar, pero no publicar (2).

La tesis universitaria es una investigación que culmina los estudios de pregrado o posgrado, se caracteriza por ser inédita y original, permite consolidar la formación académica, y obtener un título profesional, por lo que debería ser comunicada a través de canales formales en revistas dirigidas hacia la comunidad científica (3). Coincidimos con Alarcon-Ruiz \& Quezada cuando recomiendan que "las universidades tengan en cuenta al momento de la selección de docentes para asesorar una tesis, que posean conocimientos y experiencia en investigación no solo teóricos, sino también prácticos" (1).

En estudios anteriores (4) se encontró que el tener asesoría fue un factor asociado a mayores frecuencias de publicación de trabajos de investigación realizados por estudiantes de pregrado. Sin embargo, puede darse el caso de que, aunque los alumnos tengan una guía, estos no lleguen a publicar sus tesis, lo cual pudiera estar condicionado por la poca preparación de dichos tutores en materia de investigación, redacción y publicación científicas $(5,6)$.

Como fundamento esencial del discernimiento de lo que es la ciencia y lo que es la técnica, se ha comprobado que no todo profesor universitario es un investigador o un científico. Es necesario seleccionar los docentes entre los investigadores, pues si ambos perfiles coinciden en una misma persona sería ideal por estar la mayor parte del tiempo en contacto directo con los estudiantes. Estos profesores-investigadores pueden participar activamente en la formación de profesionales competentes y exitosos en materia de investigación y publicación científicas (7). En otras palabras, sólo un docente que realmente investigue y publique, por su experiencia, tendrá la credibilidad para la enseñanza de la investigación. Esto, debido a que esa misma experiencia le dará la sabiduría para enseñar (8) y demostrar con su ejemplo las ventajas de la investigación y publicación científicas (7).

En el caso específico de las ciencias médicas en Cuba, lo que está normado es que los estudiantes se gradúen a partir de un examen estatal. Ello implica que hasta que el médico graduado no se haga especialista, no tiene que redactar un texto científico. En diversas universidades médicas latinoamericanas, está estipulado el desarrollo de una tesis como requisito indispensable para obtener el título. Aunque esto es positivo porque necesariamente se requiere adquirir habilidades de redacción científica, una vez obtenido el título, muchas veces sus resultados nunca llegan a concretarse por medio de la publicación científica (7).

Ante esta realidad, algunas universidades han desarrollado una propuesta distinta en relación al formato de cómo hacer la tesis, al cambiar su estructura de manera que esta se redacte en el formato de un artículo científico, e incluso se envíe a publicar a una revista de calidad, por cuanto estas tesis son trabajos de investigación y deberían ser publicadas

\footnotetext{
Universidad de Ciencias Médicas de Granma. Hospital Provincial Universitario Carlos Manuel de Céspedes. Granma-Cuba.

Universidad Técnica de Cotopaxi, Campus La Maná. Latacunga-Ecuador.

Universidad Técnica Estatal de Quevedo. Quevedo, Los Ríos-Ecuador.

Clínica Privada. Guayaquil-Ecuador.
} 
(9). Esta alternativa ha tenido un impacto positivo en el número de investigaciones publicadas (10), y resultaría favorable extenderla a las universidades que tienen como requisito para titularse la realización de una tesis, pues es mundialmente reconocido que las investigaciones que no se publican no existen.

\section{Ibraín Enrique Corrales-Reyes ${ }^{1}$, Juan José Reyes- Pérez $^{2,3}$, Mayra Lorena Díaz-Santoya ${ }^{4}$}

\section{Correspondencia:}

Ibraín Enrique Corrales-Reyes.

Ignacio Pérez \# 12A e/ Avenida 26 de Julio y

Donato Mármol. CP: 87300. Jiguaní-Granma, Cuba.

Teléfono: (+53) 54776584. ORCID: 0000-0002-

2146-9014.

E-mail: iecorralesr@infomed.sld.cu

\section{REFERENCIAS BIBLIOGRÁFICAS}

1. Alarcon-Ruiz CA, Quezada MA. Publicación de artículos científicos por asesores de tesis de una Facultad de Medicina. Rev Med Hered [Internet]. 2018 [citado 21 de noviembre de 2018]; 29:152-157. Disponible en: https://doi.org/10.20453/rmh. v29i3.3403

2. Corrales-Reyes IE \& Castro-Rodríguez Y. Scientific output in Dentistry: a look toward the undergraduate in Latin America. J Oral Res [Internet]. 2018 [citado 21 de noviembre de 2018]; 7(5):168-169. Disponible en: http://dx.doi.org/10.17126/joralres.2018.042

3. Castro-Rodríguez Y. Indicadores bibliométricos de las tesis sustentadas por estudiantes de Odontología, Perú. EDUMECENTRO [Internet]. 2018 [citado 21 de noviembre de 2018];10(4):1-19. Disponible en: http://www.revedumecentro.sld.cu/index.php/ edumc/article/view/1099

4. Valladares-Garrido MJ, Flores-Pérez I, Failoc-Rojas VE, Mariñas-Miranda W, Valladares-Garrido D, Mejia CR. Publicación de trabajos presentados a congresos científicos internacionales de estudiantes de medicina de Latinoamérica, 2011-2014. Educ Med [Internet].
2017 [citado 21 de noviembre de 2018];18(3):167173. Disponible en: http://dx.doi.org/10.1016/j. edumed.2016.06.013

5. Mejia CR, Valladares-Garrido MJ, Valladares Garrido D. Baja publicación en revistas científicas de médicos peruanos con doctorado o maestría: frecuencia y características asociadas. Educ Med [Internet]. 2017 [citado 21 de noviembre de 2018]. Disponible en: https://doi.org/10.1016/j.edumed.2017.01.009 [en prensa]

6. Pereyra-Elías R, Huaccho-Rojas JJ, Taype-Rondan Á, Mejia CR, Mayta-Tristán P. Publicación y factores asociados en docentes universitarios de investigación científica de escuelas de medicina del Perú. Rev Peru Med Exp Salud Pública [Internet]. 2014 [citado 21 de noviembre de 2018]; 31:424-30. Disponible en: https://www.scielosp.org/pdf/rpmesp/2014. v31n3/424-430/es

7. Corrales-Reyes IE, Dorta-Contreras AJ. Students' scientific production: a proposal to encourage it. Medwave [Internet]. 2018 [citado 21 de noviembre de 2018];18(1):e7166. Disponible en: http://dx.doi. org/10.5867/medwave.2018.01.7166

8. Morales-Chávez M. El rol del docente investigador en Odontología. Odontol Sanmarquina [Internet]. 2017 [citado 21 de noviembre de 2018]; 20(2):8993. Disponible en: http://dx.doi.org/10.15381/ os.v20i2.13939

9. Mayta-Tristán P. Tesis en formato de artículo científico: oportunidad para incrementar la producción científica universitaria. Acta Med Peru [Internet]. 2016 [citado 21 de noviembre de 2018]; 33(2):958. Disponible en: http://www.scielo.org. pe/scielo.php?script $=$ sci_arttext\&pid $=$ S1728 59172016000200001\&lng=es

10. Jimenez F. Pregrado en medicina humana: ¿es posible graduarse publicando? Rev Med Hered [Internet]. 2013 [citado 21 de noviembre de 2018]; 24(2):17577. Disponible en: http://www.scielo.org.pe/scielo. php?pid=S1018-130X2013000200015\&script $=$ sci arttext

Recibido: $21 / 11 / 2018$ 